\title{
Caroli disease
}

INSERM

\section{Source}

INSERM. (1999). Orphanet: an online rare disease and orphan drug data base. Caroli disease. ORPHA:53035

Caroli disease (CD) is a rare congenital liver disease characterized by non-obstructive cystic dilatations of the intra-hepatic and rarely extra-hepatic bile ducts. 